\title{
Neurologic Course, Endocrine Dysfunction and Triplet Repeat Size in Spinal Bulbar Muscular Atrophy
}

\author{
Michael Sinnreich, Eric J. Sorenson, Christopher J. Klein
}

\begin{abstract}
Objective: To study the role of diabetes, gynecomastia and CAG triplet repeat size as disease modifying factors of neurologic expression in spinal bulbar muscular atrophy (SBMA, Kennedy's disease). Methods: Twenty unrelated SBMApatients with confirmatory genetic testing were reviewed. Patterns of neurologic involvement were assessed (e.g. bulbar, asymmetric, proximal, distal, motor and sensory). Slopes of disease progression were calculated from serial quantified neurologic examinations. Patterns of neurologic involvement and course were correlated to the presence of diabetes, gynecomastia and triplet repeat size. Results: Diabetes or glucose impairment occurred in nine and 11 had gynecomastia. Patterns of neurologic involvement and rates of progression did not correlate with these endocrine diseases or triplet repeat sizes. Correlation was seen between number of CAG repeats and age of onset weakness $\left(r=-0.53, r^{2}=29 \%, p=0.01\right)$. Conclusions: The specific neurotoxic effect of expanded CAGs appears limited to age of onset weakness in SBMA. Although significant, only $29 \%$ of the variability in onset age could be accounted for by polyglutamine size suggesting the importance of other unidentified factors. In this series diabetes or glucose impairment was more common than previously reported and, like gynecomastia, did not correlate with size of triplet repeats, severity or patterns of neurologic involvement. Modifying factors other than diabetes, gynecomastia or triplet repeat size are suggested in disease expression.
\end{abstract}

RÉSUMÉ: Évolution neurologique, dysfonction endocrinienne et taille de l'expansion des répétitions du triplet dans l'amyotrophie bulbo-spinale. Objectif: Étudier le rôle du diabète, de la gynécomastie et de la taille de l'expansion des répétitions du triplet CAG comme facteurs modifiant l'expression neurologique de l'amyotrophie bulbo-spinale (AMBS, maladie de Kennedy). Méthodes: Les dossiers de vingt patients non apparentés, atteints d'AMBS dont le diagnostic avait été confirmé par un test génétique, ont été révisés. Le tableau neurologique a été évalué et classifié, soit bulbaire, asymétrique, proximal, distal, moteur ou sensitif. Des examens neurologiques quantifiés successifs ont servi à calculer le taux de progression de la maladie. Le tableau neurologique et l'évolution ont été corrélés à la présence de diabète et de gynécomastie et à la taille de l'expansion du triplet CAG. Résultats: Le diabète ou l'intolérance au glucose était présent chez neuf patients et la gynécomastie chez 11. Le tableau neurologique, le taux de progression ou la taille de l'expansion du triplet CAG n'étaient pas corrélés à ces maladies endocriniennes. Il existait une corrélation entre le nombre de répétitions CAG et l'âge de début de la faiblesse musculaire $(r=-0,53 ; r 2=29 \% ; p=0,01)$. Conclusions: L'effet neurotoxique spécifique de l'expansion CAG semble limité à l'âge de début de la faiblesse musculaire dans l'AMBS. Bien que significatif, seulement $29 \%$ de la variabilité de l'âge de début pouvait être attribuée à la taille de la polyglutamine, ce qui suggère que d'autres facteurs non encore identifiés sont importants. Dans notre série de patients, le diabète ou l'intolérance au glucose était plus fréquent que ce qui a été rapporté antérieurement et il n'existait pas de corrélation entre la présence de ces pathologies ou de la gynécomastie et le nombre de répétitions $\mathrm{CAG}$, la sévérité ou le tableau neurologique. Nous suggérons qu'il existe des facteurs modificateurs autres que le diabète, la gynécomastie ou le nombre de répétitions CAG qui influencent l'expression de la maladie.

Can. J. Neurol. Sci. 2004; 31: 378-382

Spinal bulbar muscular atrophy (SBMA, Kennedy's disease [MIM 313200]) is caused by expanded polyglutamines encoded by exon 1 of the androgen receptor gene. ${ }^{1}$ Patients have varied involvement of the lower motor and sensory neurons and endocrine systems, including diabetes and gynecomastia. ${ }^{2,3}$
From the Peripheral Neuropathy Research Laboratory, Department of Neurology, Mayo Clinic and Mayo Foundation, Rochester, MN USA.

ReCeived July 14, 2003. ACCEPTED INFINALFORM DeCEMBER 22, 2003. Reprint requests to: Christopher J. Klein, 200 First Street SW, Rochester, MN 55905 USA 
Severity of disease has been linked to increased size of expansions in other nucleotide repeat diseases. In SBMA this association has met with uncertainty and has best been demonstrated in Japanese populations. ${ }^{4,5}$ Two studies with Caucasian patients suggested correlation between size of triplet repeats and age of onset weakness. ${ }^{6,7}$ However, the largest study with Caucasians did not show this association when Japanese patients were excluded. ${ }^{8}$ Quantified evaluation of disease progression in SBMAis lacking.

Understanding which modifying factors influence SBMA clinical course is important in designing relevant treatment strategies as correction of the underlying genetic defect is currently not available. Androgens are important in determining muscle mass as well as strength and have trophic effects on diverse neuronal populations. However, reduction of testosterone in a transgenic mouse model of SBMA prevents disease expression. ${ }^{10}$ This may be explained by reduced transfer of toxic polyglutamines into the nucleus when testosterone levels are diminished. ${ }^{10}$ Gynecomastia in SBMA has been correlated with elevated testosterone levels ${ }^{9}$ and, therefore, patients with gynecomastia might be predicted to have worse disease given the observations in animal models.

The extent of sensory involvement in some patients raises questions as to the classification of this disorder as a pure motor neuronopathy. ${ }^{11}$ Because diabetes occurs in this disease, it might be thought to account for the sensory involvement seen in some patients. Investigation into the association of diabetes and sensory loss in SBMA is lacking. Similarly, the asymmetric motor presentations seen in SBMAhave not been correlated with the presence of diabetes. Asymmetric motor predominant syndromes may occur in diabetes.

We wished to determine, in SBMA patients, whether neurologic presentations or rates of progression correlated with the presence of gynecomastia or diabetes and triplet repeat size.

\section{METHODS}

\section{Patients and Clinical Evaluations}

Using a computerised record retrieval system, all charts of patients diagnosed with SBMA at the Mayo Clinic, Rochester, $\mathrm{MN}$, were reviewed. Only patients with confirmatory genetic testing, i.e. CAG repeats greater than 35, were included (20 patients). Neurologists specialising in neuromuscular disorders performed all examinations, and patients gave consent as reviewed by our Institutional Review Board. To quantify neurologic abnormality a validated scale, Neuropathy Impairment Score (NIS), was utilised. ${ }^{12}$ The NIS scale was modified (NIS ${ }^{\text {mod }}$ ) to include only those muscle groups which had been recorded in all patients and which could therefore be used comparatively: extraocular, facial, palate, respiratory, shoulder abduction, elbow flexion, elbow extension, finger spread, thumb abduction, hip flexion, knee flexion, knee extension, ankle dorsiflexion, ankle plantar flexion and toe extension. Muscle weaknesses were scored from 0 points, being normal to 4 points being flaccid without trace movement. Reduction of strength by $25 \%$ from normal was scored as 1 point, $50 \%$ weakness was scored as 2 points and $75 \%$ weakness as 3 points. All NIS components of sensory (light touch, pin prick, vibration, proprioception) and reflex abnormalities (brachioradialis, biceps, triceps, patellar, Achilles) were scored. All patients had assessment for the presence of diabetes. Diabetes was determined by fasting blood glucose greater than $126 \mathrm{mg} / \mathrm{dL}$ or glucose impairment by fasting glucose between $110-125 \mathrm{mg} / \mathrm{dL}$ according to recently published criteria. ${ }^{13}$ One patient had only one single measurement of fasting blood glucose level at $143 \mathrm{mg} / \mathrm{dl}$ and was considered diabetic. The presence of gynecomastia was assessed in 17 patients by clinical examination.

Slopes of disease progression were calculated for eight patients with serial examinations. Linear regression was performed in patients in whom more than two time points were available, otherwise the slope was calculated as $\Delta$ NIS $^{\text {mod }}$ / $\Delta$ time(years). The relationship between $\mathrm{CAG}$ repeat length, age of onset weakness, presence of diabetes or gynecomastia and slope of disease progression was examined by calculating bivariate correlation coefficients.

\section{RESUltS}

Patients were Caucasians and unrelated as determined from medical genetic consultations. Reported age of weakness onset ranged from 19 to 75 years and triplet repeat sizes from 36 to 55 . Varied patterns of reported onset weakness were noted (six bulbar, eight proximal, four distal, one proximal and distal, one neurologically asymptomatic). The asymptomatic patient was referred for evaluation of an unexplained creatine kinase elevation, and developed weaknesses. Two reported asymmetric onset extremity weaknesses and an additional two reported symptoms characteristic of a length dependent motor predominant polyneuropathy. Reported age of onset correlated with triplet repeat length $(\mathrm{r}=-0.53, \mathrm{p}=0.01)$, (Figure).

First clinical examination at our institution varied from 0 to 19 years from reported onset weakness. Twelve had bulbar, proximal and distal limb weakness at time of their first neurologic examination at our institution. Of those, nine had

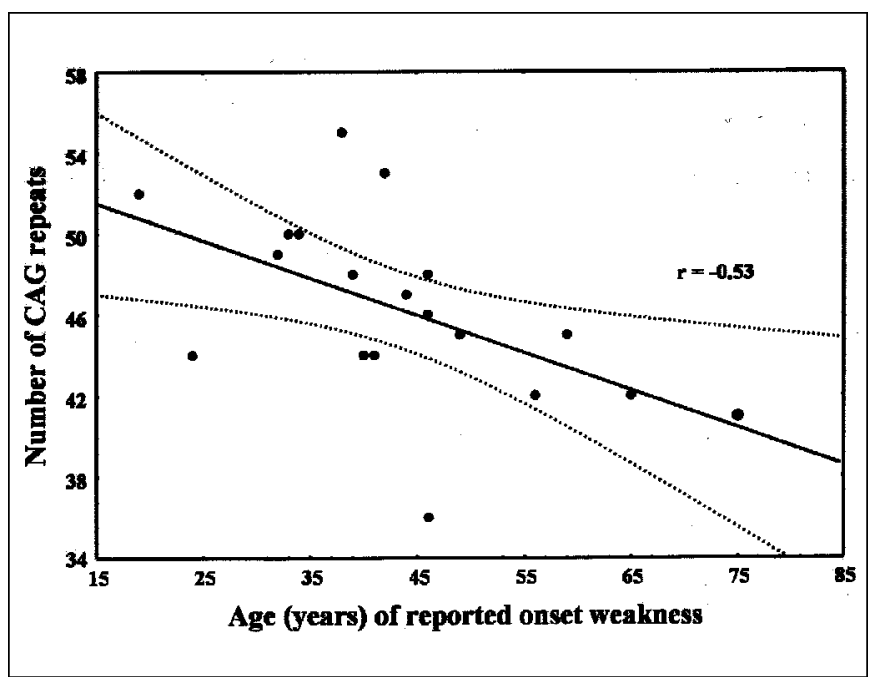

Figure: Correlation between the number of CAG repeats in the androgen receptor gene and reported onset weakness in 20 unrelated Caucasian SBMA patients, $r=-0.53, p=0.01$. The dotted curves indicate $95 \%$ confidence limits. 
THE CANADIAN JOURNAL OF NEUROLOGICAL SCIENCES

Table 1: Age and NIS ${ }^{\text {mod }}$ of 20 Kennedy's disease cohort patients

\begin{tabular}{|c|c|c|c|c|c|c|}
\hline Patient & $\begin{array}{c}\text { Age } \\
\text { at first } \\
\text { presentation } \\
\left(\text { NIS }^{\text {mod }}\right)\end{array}$ & $\begin{array}{c}\text { Age } \\
\text { at second } \\
\text { presentation } \\
\left(\text { NIS }^{\text {mod }}\right)\end{array}$ & $\begin{array}{c}\text { Age } \\
\text { at third } \\
\text { presentation } \\
\left(\text { NIS }^{\text {mod }}\right)\end{array}$ & $\begin{array}{c}\text { Age } \\
\text { at fourth } \\
\text { presentation } \\
\left(\text { NIS }^{\text {mod }}\right)\end{array}$ & $\begin{array}{c}\text { Age } \\
\text { at fifth } \\
\text { presentation } \\
\left(\text { NIS }^{\text {mod }}\right)\end{array}$ & $\begin{array}{c}\text { Course } \\
\text { NIS }^{\text {mod/year }}\end{array}$ \\
\hline 2 & $36(49)$ & $41.5(45)$ & $42(52)$ & $44.5(70)$ & $47(78)$ & 2.9 \\
\hline 3 & $42(56)$ & & & & & \\
\hline 4 & $38(34)$ & & & & & \\
\hline 7 & $40(10)$ & & & & & \\
\hline 8 & $50(18)$ & & & & & \\
\hline 9 & $42(29)$ & $47(42)$ & $49.3(48)$ & $50(51)$ & & 2.6 \\
\hline 10 & $41(8)$ & $55(16)$ & & & & 0.6 \\
\hline 11 & $44(54)$ & & & & & \\
\hline 16 & $55(36)$ & $63(71)$ & & & & 4.7 \\
\hline 17 & $59(14)$ & $60(22)$ & & & & 6.7 \\
\hline 18 & $59(5)$ & $78(60)$ & & & & 2.9 \\
\hline 19 & $75(40)$ & & & & & \\
\hline 20 & $77(56)$ & & & & & \\
\hline
\end{tabular}

NIS ${ }^{\text {mod: }}$ modified neuropathy impairment score, see methods.

Table 2: Clinical summary of 20 Kennedy's disease cohort patients

\begin{tabular}{|c|c|c|c|c|c|}
\hline Patient & $\begin{array}{c}\text { Age } \\
\text { at reported } \\
\text { onset weakness }\end{array}$ & $\begin{array}{l}\text { Number of } \\
\text { repeats }\end{array}$ & $\begin{array}{l}\text { Diabetes, Glucose } \\
\text { impairment }\end{array}$ & Gynecomastia & $\begin{array}{l}\text { Most recent clinical } \\
\text { examination }\end{array}$ \\
\hline 1 & 19 & 52 & No & Yes & BSP \\
\hline 3 & 32 & 49 & No & Yes & BSPD-Sens \\
\hline 4 & 33 & 50 & Glc imp & No & BSPD \\
\hline 5 & 34 & 50 & Glc imp & Yes & BSPD-Sens \\
\hline 7 & 39 & 48 & No & Yes & BSPD \\
\hline 8 & 40 & 44 & No & Yes & DA-Sens \\
\hline 9 & 41 & 44 & Diabetes & Yes & BSPD-Sens \\
\hline 10 & 41 & 44 & No & Yes & BSD-Sens \\
\hline 11 & 42 & 53 & Diabetes & NR & BSPD-Sens \\
\hline 12 & 44 & 47 & No & NR & BSPD-Sens \\
\hline 17 & 56 & 42 & Glc imp & NR & $\mathrm{B}$ \\
\hline 18 & 59 & 45 & No & No & BAPD-Sens \\
\hline 19 & 65 & 42 & Diabetes & Yes & BSPD-Sens \\
\hline 20 & 75 & 41 & No & No & BSPD-Sens \\
\hline
\end{tabular}

A: asymmetric distribution of weakness; B: bulbar weakness; D: distal weakness; Glc imp: glucose impairment; NR: not recorded; P: proximal weakness; S: symmetric distribution of weakness; Sens: distal sensory involvement 
lower limb distal sensory involvement. Six had asymmetric weakness on examination.

Up to five serial exams were available in eight patients over a time period of one to nineteen years with the examination patterns noted (Tables 1 and 2). Among these eight the slope of disease progression did not correlate with triplet repeat size. We note that at least three patients had subacute decline in neurological function (Patients 2, 5, 12), (Table 1).

Six had adult onset diabetes mellitus and three had impaired fasting glucose. Two of the diabetics required insulin therapy, two were on oral hypoglycemic medication and two were diet controlled and none had end organ complications of diabetes. We observe that in patients with diabetes or glucose impairment there was no association with age of onset. There was no association with diabetes and glucose impairment with size of triplet repeats. There was no association with pattern of clinical involvement expected with diabetes i.e. distal-sensory or proximal-asymmetric-motor, (Table 2).

Eleven had gynecomastia and six did not. Patients with gynecomastia did not have worse progression and no association was found between patterns of impairment and onset of weakness. Presence of gynecomastia did not correlate with size of triplet repeats and even patients with small expansions had gynecomastia, (Table 2). Rates of progression did not correlate with gynecomastia, (Tables 1, 2).

\section{Discussion}

Clinical rating scales provide important tools in the understanding of the natural history of neurologic disease. Because progressive neurologic impairments often occur without newly described handicaps, serial quantitative clinical exams are advantageous in understanding disease course. We utilised the serial NIS ${ }^{\text {mod }}$ because it is age corrected and accounts for muscle weaknesses in cranial, proximal and distal upper and lower extremity distribution and includes reflex and distal sensory changes, all of which can be encountered in SBMA.

In our 20 patients, eight had serial quantified clinical examinations and our analysis suggests there is no correlation between the number of CAG repeats and the rate of disease progression. The strength of the observation is limited, however, by small sample size, variation in length of follow-up and varied triplet repeat sizes between individuals. These limitations are largely unavoidable given that this is such a rare disorder. Regardless, the findings would be consistent with the additional observation that individuals of the same family with similar repeat length may have obvious variability in disease progression. ${ }^{14}$

We found a significant correlation between number of triplet expansions and age of reported onset weakness. Although only a small portion $\left(\mathrm{r}^{2}=29\right.$ percent $)$ of the variability of onset weakness could be accounted for by the size of polyglutamine expansions. Combined with the observations of others we believe the data should emphasise the variability of onset weakness with size of triplet repeat expansions. The neurotoxic gain of function with expanded polyglutamines in SBMAmay be weak in comparison with other triplet repeat diseases. However, we note that the reported correlation between age of disease onset and triplet repeat size is stronger in studies with SBMA patients of Japanese origin. ${ }^{4,5,8}$ This may point to possible varied disease modifying factors in certain ethnicities. At least three of our patients had time periods with subacute decline in neurological function. Such a phenomenon had been reported in one other patient ${ }^{14}$ and may, in fact, be more frequent in SBMA than intuitively anticipated from a seemingly chronic neuronopathy.

We reviewed for diabetes as a potential modifier of disease beyond triplet repeat size. Approximately half of the patients in our cohort had diabetes or were glucose impaired which is more frequent than previously reported. ${ }^{2,9}$ Why diabetes is likely to occur in this disease is unknown, and has been reported in other nucleotide repeat diseases without clear explanation. We observe that our more severe patients were no more likely to have diabetes or glucose impairment suggesting that decreased mobility or activity may not be the cause of their diabetes. Although the power of our study is limited, diabetes does not appear to play a major role in age of disease onset or rates of progression. The distal sensory or asymmetric motor features of SBMA did not appear more commonly in those patients with diabetes. In fact six patients without diabetes or glucose impairment had clear distal sensory loss.

Lastly, we considered whether gynecomastia might associate with worse progression and hence a potential marker of disease course. Because gynecomastia associates with elevated testosterone levels in SBMA, ${ }^{9}$ and testosterone induces phenotypic expression in transgenic SBMA mice, ${ }^{10}$ one might have expected gynecomastia to correlate with worse neurologic course. In our limited series the presence of gynecomastia did not correlate with age of disease onset, rate of progression or neurologic impairments. Although we did not find any significant correlation between the presence of gynecomastia and the number of CAG triplets, others have observed a relationship between age of onset of gynecomastia and CAG triplet length. ${ }^{9}$ Our patients without gynecomastia had no better course than those with gynecomastia. This data would be consistent with the theory that testosterone, independent of level, is sufficient to lead to expression of SBMA and would be in keeping with the recently described animal models..$^{10,15}$

Although the size of expanded repeats did correlate with earlier disease onset, the varied and unpredictable rates of progression complicate the council of patients and will ultimately make clinical trials difficult. We suggest that diabetes and gynecomastia may not be important in neurologic course or expression, but the power of our statement is limited, as is our observation that diabetes may be more common in this disease than previously appreciated. Additional work will be needed to identify specific disease modifiers, as correction of the underlying genetic defect is currently not possible.

\section{REFERENCES}

1. La Spada AR, Wilson EM, Lubahn DB, et al. Androgen receptor gene mutations in X-linked spinal and bulbar muscular atrophy. Nature 1991;352(6330):77-79.

2. Harding AE, Thomas PK, Baraitser M, et al. X-linked recessive bulbospinal neuronopathy: a report of ten cases. J Neurol Neurosurg Psychiatry 1982;45(11):1012-1019.

3. Kennedy WR, Alter M, Sung JH. Progressive proximal spinal and bulbar muscular atrophy of late onset. A sex-linked recessive trait. Neurology 1968;18(7):671-680. 
4. Shimada N, Sobue G, Doyu M, et al. X-linked recessive bulbospinal neuronopathy: clinical phenotypes and $\mathrm{CAG}$ repeat size in androgen receptor gene. Muscle Nerve 1995;18(12):1378-1384.

5. Igarashi S, Tanno Y, Onodera O, et al. Strong correlation between the number of CAG repeats in androgen receptor genes and the clinical onset of features of spinal and bulbar muscular atrophy. Neurology 1992;42(12):2300-2302.

6. Sperfeld AD, Karitzky J, Brummer D, et al. X-linked bulbospinal neuronopathy: Kennedy disease. Arch Neurol 2002;59(12):19211926.

7. La Spada AR, Roling DB, Harding AE, et al. Meiotic stability and genotype-phenotype correlation of the trinucleotide repeat in Xlinked spinal and bulbar muscular atrophy. Nat Genet 1992;2(4):301-304.

8. Lund A, Udd B, Juvonen V, et al. Multiple founder effects in spinal and bulbar muscular atrophy (SBMA, Kennedy disease) around the world. Eur J Hum Genet 2001;9(6):431-436.

9. Dejager S, Bry-Gauillard H, Bruckert E, et al. A comprehensive endocrine description of Kennedy's disease revealing androgen insensitivity linked to $\mathrm{CAG}$ repeat length. J Clin Endocrinol Metab 2002;87(8):3893-3901.

10. Katsuno M, Adachi H, Kume A, et al. Testosterone reduction prevents phenotypic expression in a transgenic mouse model of spinal and bulbar muscular atrophy. Neuron 2002;35(5):843-854.

11. Antonini G, Gragnani F, Romaniello A, et al. Sensory involvement in spinal-bulbar muscular atrophy (Kennedy's disease). Muscle Nerve 2000;23(2):252-258

12. Dyck PJ, Davies JL, Litchy WJ, et al. Longitudinal assessment of diabetic polyneuropathy using a composite score in the Rochester Diabetic Neuropathy Study cohort. Neurology 1997;49(1):229-239.

13. Report of the expert committee on the diagnosis and classification of diabetes mellitus. Diabetes Care 2003;26 (Suppl 1):S5-20.

14. Amato AA, Prior TW, Barohn RJ, et al. Kennedy's disease: a clinicopathologic correlation with mutations in the androgen receptor gene. Neurology 1993;43(4):791-794.

15. Takeyama K, Ito S, Yamamoto A, et al. Androgen-dependent neurodegeneration by polyglutamine-expanded human androgen receptor in Drosophila. Neuron 2002;35(5):855-864. 